\title{
Atividade da Tripsina em Rã-Touro na Fase Pós-Metamórfica1
}

\section{Luís Gustavo Tavares Braga ${ }^{2}$, Maria Goreti de Almeida Oliveira ${ }^{3}$, William Cardoso Lima ${ }^{4}$, Ricardo Frederico Euclydes ${ }^{5}$}

\begin{abstract}
RESUMO - Com o objetivo de avaliar a atividade enzimática da tripsina no conteúdo intestinal da rã-touro (Rana catesbeiana Shaw, 1802), 320 animais com peso médio de 3,6 g foram distribuídos em baias-teste com temperatura e fotoperíodo controlados. As rãs selecionadas na fase pós-metamórfica receberam ração comercial extrusada ad libitum. Durante 87 dias de experimento, foram efetuadas 29 coletas em intervalos de 1 a 8 dias. As coletas do conteúdo intestinal foram feitas mediante a insensibilização das rãs em gelo e água e posterior isolamento do intestino delgado. Após cada coleta, todo o material foi congelado em nitrogênio líquido e armazenado em freezer, para posterior liofilização. A determinação da atividade da tripsina foi realizada utilizando-se Benzoil-D, L-Arginina p-nitroanilida (D, L-BApNA) como substrato. A atividade da tripsina foi registrada no primeiro dia de experimento; a fase inicial foi marcada pelo aumento da atividade da tripsina até a estabilidade, quando os animais ainda estavam na fase de imago. O período subseqüente (até o final do experimento) foi caracterizado pela manutenção da estabilidade da atividade e pela atividade específica da tripsina. Podese concluir que a rã-touro apresenta capacidade para digestão de alimentos de origem protéica, recomendando-se, na fase inicial, uso de ração rica em proteína.
\end{abstract}

Palavras-chave: atividade enzimática, enzimas digestivas, Rana catesbeiana, rã-touro, tripsina

\section{Trypsin Activity of the Bullfrog in the Post-Metamorphic Phase}

\begin{abstract}
With the objective of evaluating the enzymatic activity of the trypsin in the intestinal content of the bullfrog (Rana catesbeiana Shaw, 1802), 320 animals with average weight of 3.6 grams were distributed in stall-test with temperature and photoperiod controlled. The frogs selected in the post-metamorphic phase were fed commercial extruded diet ad libitum. For 87 days of experiment, 29 collections were performed at intervals varying from one to eight days. The collections of the intestinal content were performed by the desensitization of the frogs in ice and water and subsequent isolation of the small intestine of the same ones. After each collection, all material was frozen in liquid nitrogen and stored in freezer to be later liofilizated. The determination of the activity of the trypsin was accomplished being used benzoil-D, L-arginine p-nitroanilide (D, L-BApNA) as substrate. The activity of the trypsin was registered in the first day of experiment, and the initial phase is marked by the increase of the activity of the trypsin to reach a stability when the animals were still in the imago phase. In the subsequent period until the end of the experiment, it was observed the maintenance of the stability of the activity and specific activity of the trypsin. It can be concluded that bullfrog shows capacity for digestion of protein feedstuff, and in the initial phase the use of diet rich in protein is recommended.
\end{abstract}

Key Words: activity enzymatic, bullfrog, digestive enzymes, Rana catesbeiana, trypsin

\section{Introdução}

O comércio mundial de carnes de rãs atinge, hoje, dezenas de toneladas anuais, sendo a França e os Estados Unidos os principais consumidores e importadores do produto. Os fornecedores de rãs para o mercado mundial são, na maioria, países asiáticos. Além da criação em cativeiro, eles abastecem o mercado internacional com grandes quantidades de rãs capturadas em campos inundados e arrozais, demonstrando, porém, sinais de esgotamento nos últimos anos (Lima et al., 1999).

Com o desenvolvimento da ranicultura, novas pesquisas na área de nutrição de rãs nas fases aquática e pós-metamórfica foram executadas. Todavia, a falta de padronização de metodologias para obtenção de dados consistentes e a escassez de informações na literatura sobre alimentos e alimentação, sobretudo para rã-touro, impediram a formulação de rações compatíveis com as exigências nutricionais

\footnotetext{
1 Parte da tese de doutorado em Zootecnia, apresentada pelo primeiro autor à UFV, parcialmente financiada pelo CNPq.

2 Universidade Estadual de Santa Cruz (gbraga@uesc.br).

3 Universidade Federal de Viçosa - Lab. de Enzimologia - BIOAGRO (malmeida@ufv.br).

4 Químico (wclimax@terra.com.br).

5 Universidade Federal de Viçosa - Departamento de Zootecnia (rbaja@ufv.br).
} 
desses animais nas diferentes fases de desenvolvimento. Para alcançar esse objetivo, é preciso, antes, conhecer a biologia do animal e, então, aplicar tais conhecimentos em estudos de nutrição, considerando os ingredientes utilizados na formulação de dietas.

A eficiência de utilização dos alimentos está diretamente relacionada ao processo digestivo, no qual as enzimas são fundamentais. Portanto, o conhecimento do perfil enzimático do sistema digestivo da rã-touro favorece a escolha de ingredientes adequados ao processo metabólico do animal.

Para garantir que um programa de alimentação tenha êxito, deve-se atentar para todas as etapas da nutrição animal. Após a ingestão, o alimento sofrerá alterações físico-químicas ao longo do tubo digestivo, para então ser absorvido e metabolizado de acordo com as exigências do animal. O estudo bioquímicoenzimático das enzimas digestivas torna-se imprescindível para o melhor entendimento da fisiologia da digestão e do metabolismo dos nutrientes. Essas informações geram subsídios para trabalhos na área de nutrição e possibilitam ajustes mais precisos na elaboração de dietas.

As principais proteases do trato digestivo são pepsina, tripsina e quimotripsina. A enteroquinase presente na borda estriada dos enterócitos é responsável pela transformação do tripsinogênio em tripsina. Além disso, a tripsina hidrolisa o tripsinogênio e quimotripsinogênio em tripsina e quimotripsina, respectivamente, atuando nas ligações peptídicas que envolvem os grupos carboxila da arginina e lisina, enquanto a quimotripsina age, como a pepsina, principalmente nas ligações envolvendo aminoácidos aromáticos (Smith et al., 1988).

A tripsina e a quimotripsina foram estudadas em alguns Teleostei. De acordo com Hjelmeland \& JØrgensen (1985), a tripsina é, provavelmente, a enzima-chave na regulação e no processo digestivo em peixes jovens. Esses autores relataram a utilização do radioimunoensaio como método para quantificar tripsina e tripsinogênio em peixes.

Sabapathy \& Teo (1993), analisando a distribuição de enzimas digestivas e suas atividades no tubo digestivo de Sigamus canaliculatus (onívoro) e de Latus calcarifer (carnívoro), relataram a presença de tripsina ao longo do tubo digestivo na espécie onívora, enquanto, na espécie na carnívora, a presença desta enzima ficou restrita ao intestino e cecos pilóricos. Nessas duas espécies, também foi observada a capacidade de digestão de carboidratos.
A composição da dieta pode influenciar a liberação e atividade das enzimas digestivas. Onishi et al. (1976), comparando a freqüência da administração do alimento, em carpas, relataram mudanças nos níveis de protease e amilase após alimentação. O efeito da dieta na atividade das enzimas digestivas também foi encontrado em larvas de Dicentrarchus labrax, em um experimento executado por Cahu et al. (1998), que sugeriram a presença de algas vivas na alimentação como ponto-chave para o início das funções hidrolíticas das enzimas e desenvolvimento das membranas na borda em escova do intestino delgado. Para o "goldfish" (Carassius auratus), a atividade da tripsina, três semanas após a eclosão, foi superior em larvas alimentadas com dieta contendo náuplios de Artemia nauplii (50\%) e ração (50\%), em comparação aos animais do tratamento contendo apenas náuplios (Abi-Ayad \& Kestemont, 1994). De acordo com os autores, após esse período, as larvas tinham desenvolvido completamente o trato alimentar, não sendo mais dependentes das enzimas do alimento vivo e, dessa forma, puderam aproveitar melhor a proteína contida na ração. Seixas Filho et al. (2000), estudando a atividade enzimática da tripsina em piracanjuba (Brycon orbignyanus) e piau (Leporinus friderici), onívoros, e surubim (Pseudoplatystoma coruscans), carnívoro, concluíram que a atividade da tripsina foi semelhante nas duas últimas espécies, sugerindo que o surubim utiliza, com mais intensidade, outras proteases na digestão de proteínas.

Em experimento realizado por Zambonino-Infante et al. (1997), utilizando larvas de "sea bass" (D. labrax), alimentadas com dietas isoenergéticas e isoprotéicas, com três níveis de substituição (0, 20 e $40 \%$ ) da farinha de peixe previamente hidrolisada (75\% di- e tripeptídios), observaram que o crescimento e a sobrevivência larval foram maiores no tratamento com $40 \%$ de substituição.

Informações a respeito do estudo da atividade enzimática em anfíbios são escassas na literatura. O pepsinogênio de algumas espécies desse grupo tem sido isolado, purificado e caracterizado. Informações sobre o peso molecular, a composição aminoacídica e a posição do sítios ativos têm sugerido homologia para tais zimógenos. Detalhes de seqüências aminoacídicas e estudos de cristalografia em raio-X têm suportado esta homologia através das estruturas primária, secundária e terciária similares dos pepsinogênios de anfíbios e de outras espécies (Shugerman et al., 1982).

\section{R. Bras. Zootec., v.33, n.4, p.821-827, 2004}


Miralla et al. (1994), avaliando a secreção de pepsina em $R$. catesbeiana nas diferentes estações do ano, concluíram que, no inverno, a concentração basal de pepsina diminui significativamente, sendo máxima no verão. Estudos in vitro com a mucosa gástrica desses animais, realizados por Marroni et al. (1993) demonstraram que houve variação sazonal na secreção basal nas diferentes estações do ano e que os maiores níveis de ácido ocorreram no inverno. Neste mesmo período, houve redução significativa na secreção ácida, quando as rãs foram submetidas ao estresse osmótico.

Diante do exposto, objetivou-se avaliar a atividade enzimática da enzima digestiva tripsina no intestino delgado da rã-touro (Rana catesbeiana Shaw, 1802) pesando entre 3,6 e $200 \mathrm{~g}$.

\section{Material e Métodos}

Foram utilizados 320 exemplares de rã-touro (Rana catesbeiana Shaw, 1802) (Amphibia, Anura, Ranidae), provenientes do setor de recria do ranário Experimental do Departamento de Biologia Animal da Universidade Federal de Viçosa. Os animais foram selecionados ainda na fase de girinos, sendo efetuado, ao longo desse período, todo o trabalho de rotina de alimentação, triagem dos animais e troca de água. As instalações e o manejo utilizados seguiram aqueles adotados por Lima \& Agostinho (1992) para o sistema anfigranja.

Ao término do processo de metamorfose, quando os imagos estavam aptos para serem transferidos para o setor de recria, foi efetuada a última triagem para uniformização do peso do lote. Posteriormente, cada grupo de 80 animais com peso médio de 3,6 g foi alojado em quatro baias-teste suspensas, localizadas em salas com temperatura ambiente controlada $\left(27 \pm 1,0^{\circ} \mathrm{C}\right)$ e fotoperíodo de 12 horas de luz. Para garantir maior conforto aos animais, foi colocado na parte seca do piso, área entre os cochos e a piscina, um tecido de algodão, umedecido diariamente. Este procedimento foi realizado durante as duas primeiras semanas do experimento.

Utilizou-seumaração comercial extrusada(Tabela1), fornecida ad libitum nos cochos, juntamente com larvas de Musca domestica, para estimular e condicionar as rãs ao consumo de alimento. Inicialmente, a quantidade de larvas oferecida foi de $30 \%$ do peso da ração, sendo reduzida gradativamente durante 30 dias até alcançar $5 \%$. As trocas de alimento e água eram feitas diaria- mente pela manhã e semanalmente se efetuava uma limpeza mais criteriosa utilizando água e vassoura.

Para execução das análises de atividade enzimática de tripsina, amilase e lipase, três rãs foram amostradas das baias-teste em intervalos previamente estabelecidos, de modo a se obterem grupos de animais em diferentes faixas de peso ao longo de toda fase de desenvolvimento. Nos primeiros dez dias, as coletas do conteúdo do intestino delgado foram realizadas diariamente e, nos 77 dias restantes, mais 19 coletas em intervalos crescentes cinco para cada intervalo de dois, três e quatro dias, respectivamente, e quatro com intervalos de oito dias. A última coleta correspondeu ao dia em que foi amostrada a primeira rã com peso superior a $200 \mathrm{~g}$ (peso comercial adotado pelos ranicultores).

Após identificação, pesagem e insensibilização em água e gelo a $0^{\circ} \mathrm{C}$, as rãs sofreram incisão longitudinal ventral para exposição das vísceras e isolamento do tubo digestivo, fazendo-se ligaduras duplas nas porções cranial e caudal do intestino delgado, para evitar perdas do quimo a ser coletado e analisado. Em seguida, efetuou-se a extirpação do intestino delgado e, com o auxílio de pinça e tesoura, retirou-se deste órgão todo o conteúdo, que foi empacotado em papel alumínio, identificado com data de coleta, peso do animal, número da repetição e tipo de órgão.

Com o objetivo de garantir adequada interpretação dos resultados de atividade enzimática, retirou-se o quimo do intestino delgado apenas dos animais cujo estômago estava repleto de alimento, ou seja, a presença de alimento no estômago em quantidades similares entre as rãs sacrificadas assegurou proximidade do período de alimentação e sincronia na secreção e atuação das enzimas. Para paralisar qualquer tipo de reação, após cada coleta, todo o material embalado foi imerso em

Tabela 1 - Análise laboratorial da ração comercial Table 1 - Laboratory analysis of commercial ration

\begin{tabular}{|c|c|}
\hline $\begin{array}{l}\text { Item } \\
\text { Item }\end{array}$ & $\begin{array}{l}\text { Valor } \\
\text { Value }\end{array}$ \\
\hline Matéria seca, \% & \\
\hline $\begin{array}{l}\text { Dry matter, \% } \\
\text { Energia bruta, kcal/kg }\end{array}$ & 94,37 \\
\hline $\begin{array}{l}\text { Gross energy, } \mathrm{kcal} / \mathrm{kg} \\
\text { Proteína bruta, \% }\end{array}$ & 4533,13 \\
\hline $\begin{array}{l}\text { Crude protein, \% } \\
\text { Extrato etéreo, \% }\end{array}$ & 42,04 \\
\hline $\begin{array}{l}\text { Ether extract, \% } \\
\text { Fibra bruta, \% }\end{array}$ & 9,72 \\
\hline Crude fiber, \% & 4,99 \\
\hline
\end{tabular}


nitrogênio líquido e posteriormente armazenado em freezer com temperatura de $-40^{\circ} \mathrm{C}$. No laboratório, todas as amostras foram liofilizadas e mantidas em temperatura de $-20^{\circ} \mathrm{C}$. As análises de atividade enzimática da tripsina, amilase e lipase foram realizadas no Laboratório de Enzimologia do Instituto de Biotecnologia Aplicada à Agropecuária (BIOAGRO) - UFV.

Para preparação das amostras do quimo, foi tomado $1 \mathrm{mg}$ do material liofilizado e acondicionado em tubos plásticos e dissolvido em $0,5 \mathrm{~mL}$ de água destilada. Em seguida, a solução foi centrifugada a $35.000 \times \mathrm{g}$, a $4^{\circ} \mathrm{C}$, por 20 minutos. Posteriormente, uma alíquota do sobrenadante foi retirada para determinação da atividade enzimática da tripsina.

A determinação da atividade da tripsina foi realizada pelo método descrito por Erlanger et al. (1961), utilizando-se $500 \mu \mathrm{L}$ Benzoil-D, L-Arginia p-Nitroanilida (D, L-BApNA) como substrato. Foram retirados $300 \mu \mathrm{L}$ da amostra, ou de seu solvente no caso do tubo controle, e acrescentados $500 \mu \mathrm{L}$ da solução do substrato $6,38 \times 10^{-4} \mathrm{M}$ em tampão (TRIS-HCl 0,10 M, pH 8,2) contendo $20 \mathrm{mM}$ de $\mathrm{CaCl}_{2}$ e 1,0\% de dimetilformamida, previamente equilibrada a $25^{\circ} \mathrm{C}$. As velocidades iniciais foram deter- minadas pela formação do produto p-nitroanilida, pela medida da absorção a $410 \mathrm{nM}$, em função do tempo, utilizando-se para os cálculos o coeficiente de extinção molar de $8800 \mathrm{M}^{-1} \mathrm{~cm}^{-1}$ para o produto.

A concentração de proteína da amostra foi determinada utilizando-se a metodologia descrita por Warburg \& Christin (1941). Para obter os valores de atividade específica das enzimas digestivas no quimo, o valor da atividade de cada enzima foi dividido pelo valor da concentração de proteína obtido da respectiva amostra.

\section{Resultados e Discussão}

Os valores médios ( $\mathrm{n}=3$ ) de atividade da tripsina no quimo da rã-touro encontram-se na Figura 1. A atividade da tripsina foi verificada desde o primeiro dia de coleta do quimo, evidenciando que a rã-touro tem capacidade de digerir a proteína imediatamente após a finalização do processo de metamorfose. Esta informação está coerente com o hábito alimentar desta espécie (considerada carnívora), que se alimenta preferencialmente de pequenos animais, como insetos e larvas, em condições de natureza.

Do $1^{\circ}$ ao $8^{\circ}$ dia, o valor da atividade da tripsina

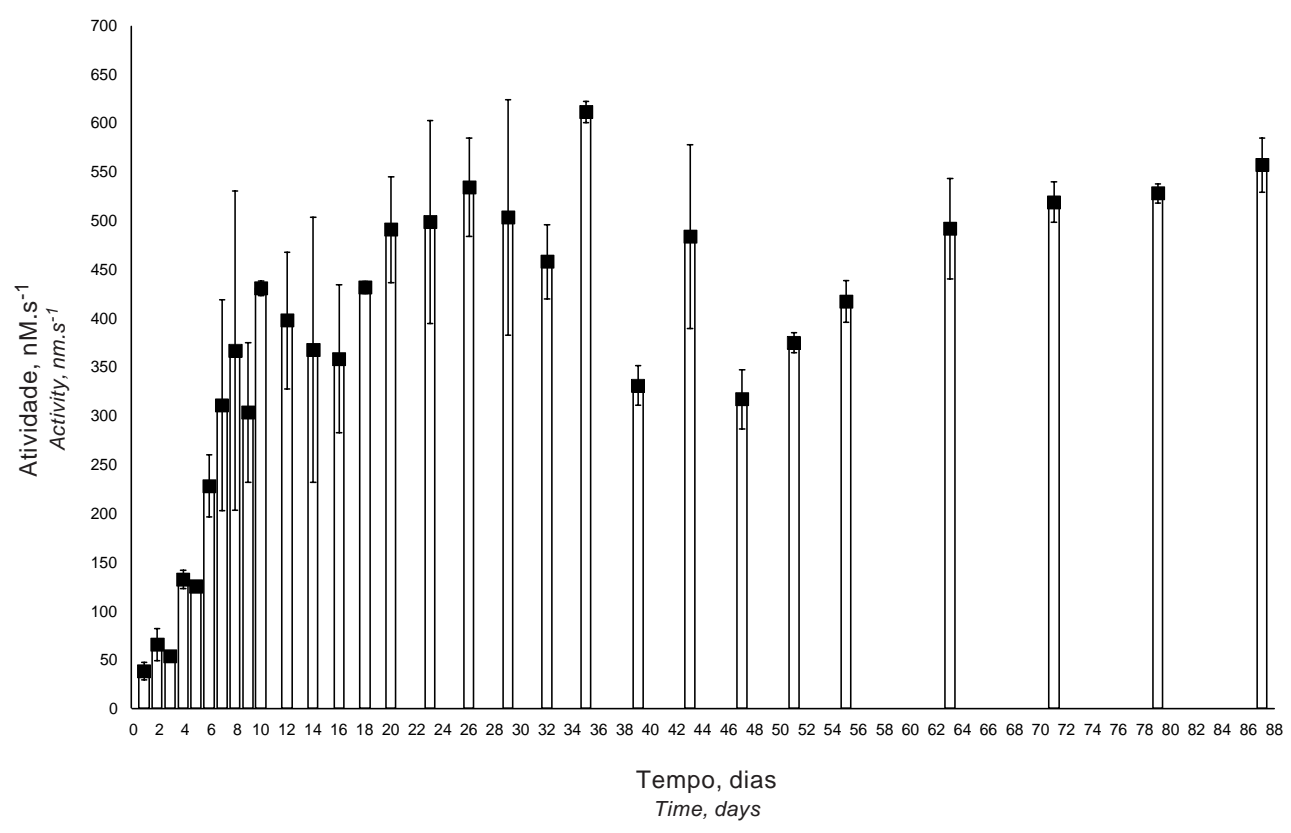

Figura 1 - Perfil da atividade da tripsina do quimo de rãs-touro alimentadas com ração comercial.

Figure 1 - Profile of the trypsin activity of chime of bullfrogs fed commercial ration.

R. Bras. Zootec., v.33, n.4, p.821-827, 2004 
apresentou tendência crescente até atingir 366,96 nM.s $\mathrm{s}^{-1}$, com taxa de crescimento de 46,92 nM. $\mathrm{s}^{-1}$ por dia. A partir deste ponto até o $18^{\circ}$ dia, com os imagos pesando $12 \mathrm{~g}$ (Figura 2), a tripsina manteve sua capacidade de hidrólise estável, atingindo média de 379 nM.s ${ }^{-1}$. Ainda na fase considerada recria inicial, entre o $18^{\circ}$ e $32^{\circ}$ dia, os imagos apresentaram um segundo período de estabilidade para atividade desta enzima, com média de 486 nM.s ${ }^{-1}$, ou seja, 28\% maior que o primeiro período. Entre o $35^{\circ}$ e $55^{\circ}$ dia, foi detectada grande variação nos valores de atividade da tripsina, que teve seu máximo (611,57 nM.s $\left.{ }^{-1}\right)$ registrado no $35^{\circ}$ dia, sendo $92,77 \%$ maior que o menor valor deste período $\left(317,26 \mathrm{nM} . \mathrm{s}^{-1}\right)$, quando as rãs aumentaram sua velocidade de crescimento, passando de 44,21 para 85,23 g em 20 dias. Isto pode ser explicado pela possível variação ocorrida na quantidade de ração ingerida, assim como pelo intervalo da alimentação à coleta do quimo, o que confere valores variáveis à velocidade da atividade enzimática.

Do 63ํ dia até o final do experimento, com as rãs adultas passando de 98,06 para 171,10 g em 26 dias, foi verificado aumento gradativo nos valores de atividade da tripsina, que passaram de 492,04 para $557,20 \mathrm{nM} . \mathrm{s}^{-1}$. Esse período correspondeu ao de maior atividade da tripsina (valor médio de 524,10 nM.s ${ }^{-1}$ ) e as rãs tiveram ganho de peso médio diário de 3,38 g contra 0,67 e 1,07 g/dia observados no primeiro e segundo períodos de estabilidade, respectivamente.

Na Figura 3, encontram-se os valores de atividade específica da tripsina no quimo da rã-touro. Do $1^{\circ}$ ao $12^{\circ}$ dia, a atividade específica da tripsina no quimo variou de 100,39 a 1389,76 nM.s ${ }^{-1} . \mathrm{mg}^{-1}$, ou seja, em 11 coletas realizadas foi registrada evolução da atividade específica desta enzima, a uma taxa de

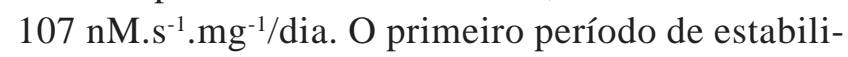
dade da atividade específica da tripsina foi encontrado entre o $14^{\circ}$ e $35^{\circ}$ dia, com média de 826 nM.s ${ }^{-1}$. $\mathrm{mg}^{-1}$, o que equivale a $57 \%$ do valor máximo observado durante as primeiras 11 coletas.

Do 39ํㅁia, quando os animais apresentaram peso médio de $43 \mathrm{~g}$, até o último dia do experimento, ocorreram oscilações nos valores da atividade específica da tripsina, cuja média foi de $878 \mathrm{nM} \cdot \mathrm{s}^{-1} \cdot \mathrm{mg}^{-1}$. Este valor foi ligeiramente superior ao verificado no período entre o 14ํㅡ e 35o dia. A média encontrada a partir do sétimo dia até o final do experimento em todo período (890 nM.s $\left.{ }^{-1} \cdot \mathrm{mg}^{-1}\right)$ foi inferior ao relatado por Seixas Filho et al. (2000), que trabalharam com surubim e obtiveram média de $1623 \mathrm{nM} . \mathrm{s}^{-1} \cdot \mathrm{mg}^{-1}$.

Os valores médios de atividade tríptica, em função do peso da rã-touro, são mostrados na Figura 4. A atividade da enzima foi crescente até o $7^{\circ}$ dia, quando foi detectado valor de $64,67 \mathrm{nM} \cdot \mathrm{s}^{-1} \cdot \mathrm{g}^{-1}$, com os animais pesando 4,41 g. Pode-se inferir que, na fase inicial, a secreção e atividade da tripsina dos imagos eram ajustadas em função do tempo, pois neste intervalo de sete dias o ganho de peso foi apenas de $0,81 \mathrm{~g}$. Do $7^{\circ}$ ao $35^{\circ}$ dia, ocorreu inversão do comportamento da atividade da tripsina, em função do peso das rãs, ou seja, os valores decresceram a uma taxa média de 1,83 nM.s. $\mathrm{s}^{-1} \cdot \mathrm{g}^{-1 / d i a}$, chegando ao valor de 13,40 nM.s-1. $\mathrm{g}^{-1}$. A capacidade de hidrólise das ligações peptídicas relacionadas à atuação da tripsina atingiu a estabilidade a partir do 39o dia e manteve-se até o final do experimento com média de $5,03 \mathrm{nM} \cdot \mathrm{s}^{-1} \cdot \mathrm{g}^{-1}$. Nesse intervalo de 48 dias, as rãs tiveram ganho de peso de $135 \mathrm{~g}$, enquanto na fase de ajuste da atividade da enzima foi apenas de 39,98 g.

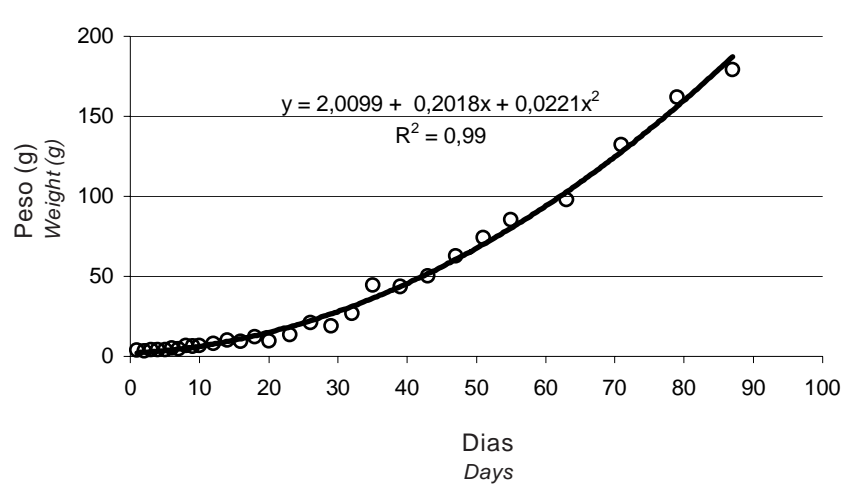

Figura 2 - Ganho de peso de rãs-touro, durante 87 dias de experimento, alimentadas com ração comercial.

Figure 2 - Weight gain of bullfrogs, for 87 days of experiment, fed commercial ration. 


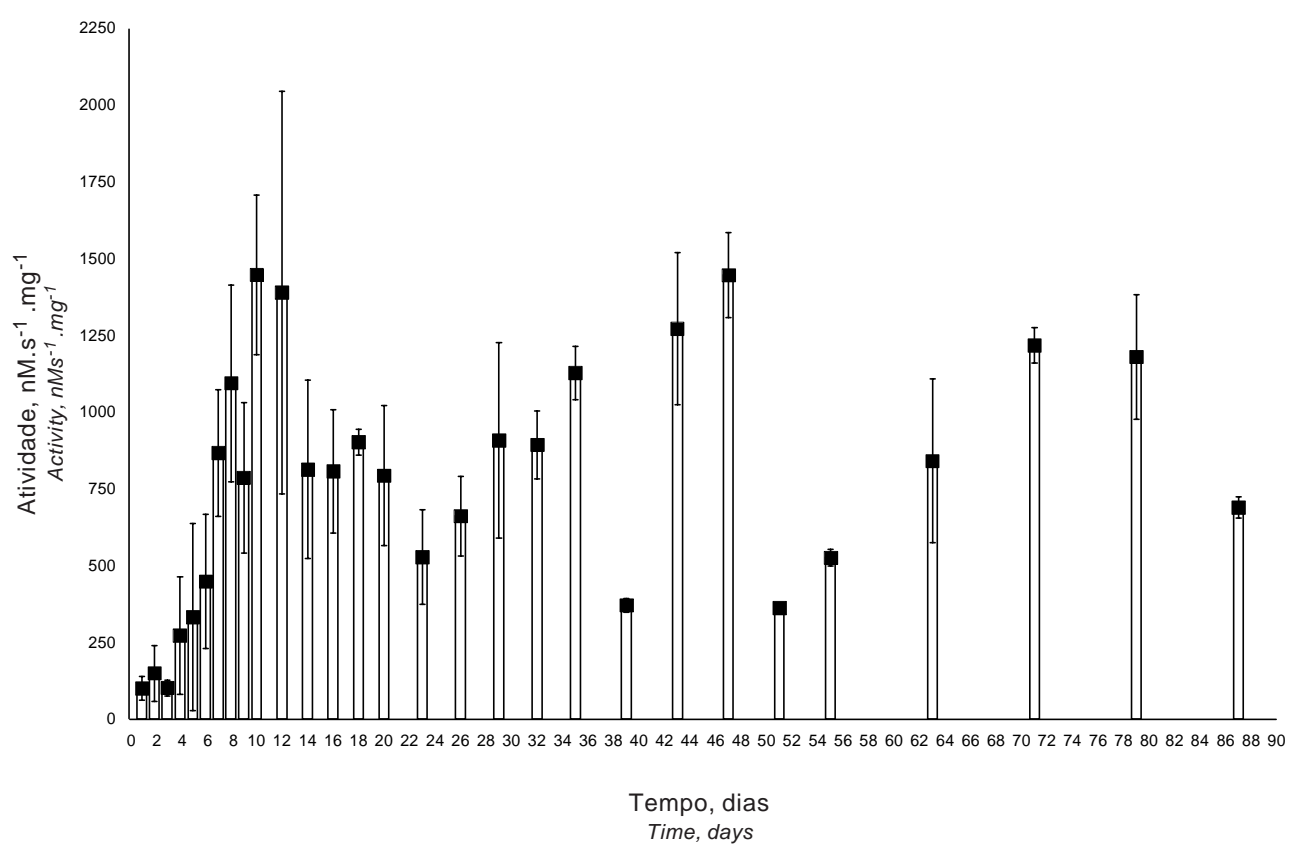

Figura 3 - Perfil da atividade específica da tripsina do quimo de rãs-touro alimentadas com ração comercial.

Figure 3 - Profile of the trypsin specific activity of the chime of bullfrogs fed commercial ration.

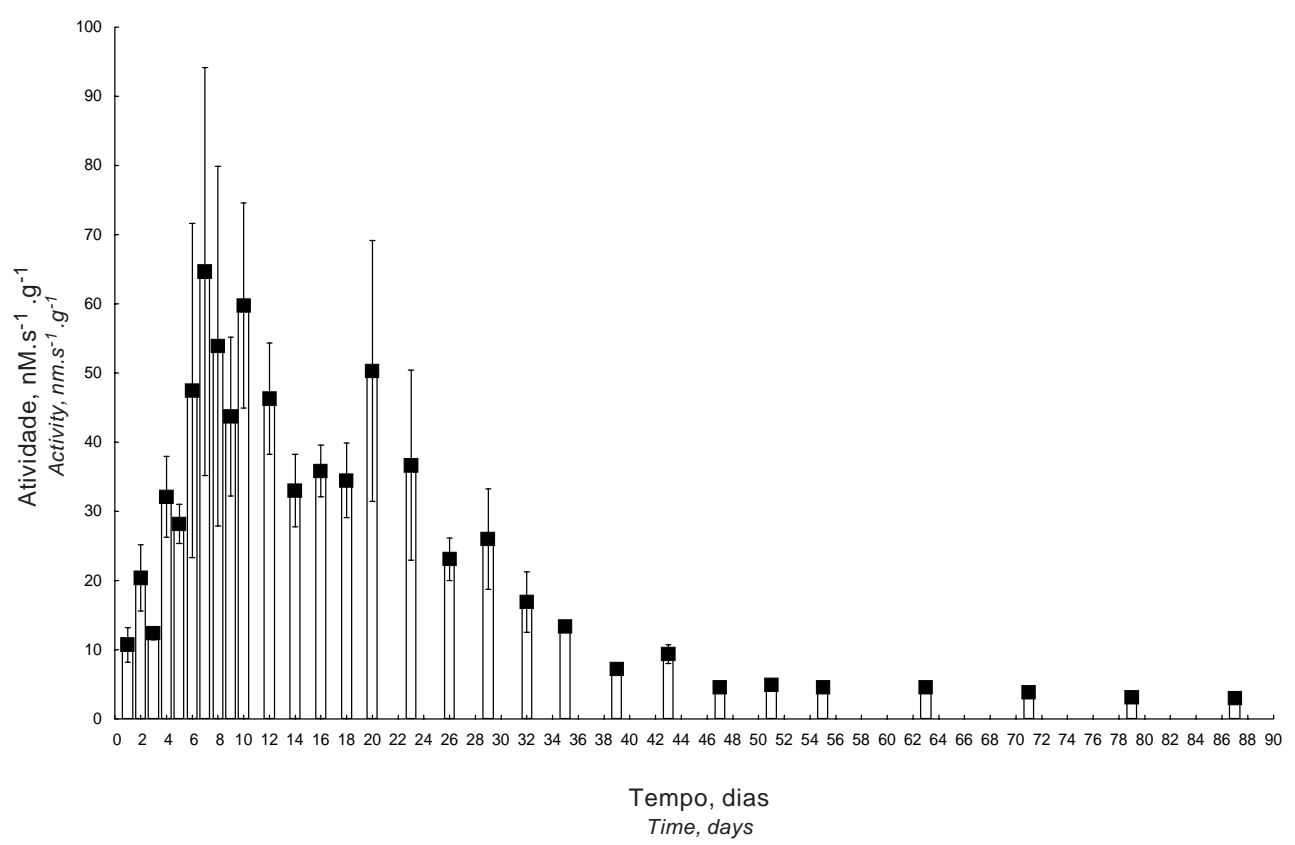

Figura 4 - Perfil da atividade da tripsina em relação ao peso das rãs-touro alimentadas com ração comercial.

Figure 4 - Profile of the trypsin activity in relation to the weight of bullfrogs fed commercial ration. 


\section{Conclusões}

Após o término da metamorfose, a rã-touro já apresenta atividade de tripsina que aumenta até alcançar estabilidade ainda na fase de imago. No período subseqüente, até o animal atingir peso médio de 200 g, há manutenção da estabilidade da atividade desta enzima, demonstrando que a rã-touro tem, inicialmente, capacidade para digerir alimentos protéicos.

\section{Literatura Citada}

ABI-AYAD, A.; KESTEMONT, P. Comparison of the nutritional status of goldfish (Carassius auratus) larvae fed with live, mixed or dry diet. Aquaculture, v.128, p.163-176, 1994.

CAHU, C.L.; ZAMBONINO-INFANTE, J.L.; PÉREZ, A. et al. Algal addition in sea bass (Dicentrarchus labrax) larvae rearing: effects on digestive enzymes. Aquaculture, v.161, p.479-489, 1998.

ERLANGER, B.F.; KOKOWWSKY, N.; CHEN, N. Archives of Biochemistry and Biophysics, v.95, p.271-278, 1961.

HJELMELAND, K.; JØRGENSEN, T. Evaluation of radioimmunoassay as a method to quantify trypsin and trypsinogen in fish. American Fish Society, v.114, p.619-621, 1985.

LIMA, S.L.; AGOSTINHO, C.A. A tecnologia de criação de rãs. Viçosa, MG: Universidade Federal de Viçosa, 1992. $168 \mathrm{p}$.

LIMA, S.L.; CRUZ, T.A.; MOURA, O.M. Ranicultura: análise da cadeia produtiva. Viçosa, MG: Editora Folha de Viçosa Ldta, 1999. 172p.

MARRONI, N.P.; MARRONI, C.A.; RODRIGUES, M.I. et al. Evaluation of gastric mucosa of na amphibiam Rana catesbeiana (Shaw) "in vivo" and "in vitro" at different seasons of the year and under the effect of stress. Arquivos de Biologia e Tecnologia, v.36, n.21, p.273-282, 1993.
MIRALLA, M.R.; MARRONI, N.P.; RODRIGUES, M.I. Avaliação da secreção de pepsina em Rana catesbeiana (Shaw) nas diferentes estações do ano, sob o efeito do estresse e do jejum prolongado. Arquivos de Biologia e Tecnologia, v.37, n.1, p.23-35, 1994.

ONISHI, T.; MURAYAMA, S.; TAKEUCHI, M. Changes in digestive enzyme levels in carp after feeding - III Response of protease and amylase to twice- a- day feeding. Bulletin of Japanese Society of Scientific Fisheries, v.42, n.8, p.921-923, 1976.

SABAPATHY, U.; TEO, L.H. A quantitative study of some digestive enzymes in the rabbitfish, Sigamus canaliculatus and the sea bass, Latus calcarifer. Journal of Fish Biology, v.42, p.595-602, 1993.

SEIXAS FILHO, J.T.; OLIVEIRA, M.G.A.; DONZELE, J.L. et al. Atividade da tripsina em quimo de três espécies neotropicais de peixes Teleostei de água doce. Revista Brasileira de Zootecnia, v.29, n.6 p.6-14, 2000. (suplemento 2)

SHUGERMAN, R.P.; HIRSCHOWITZ, B.I.; BHOWN, A.S. et al. A unique pepsinogen isolated from bullfrog esophageal glands. Journal Biological Chemistry, v.257, p.795-798, 1982.

SMITH, E.M.; HILL, R.L.; LEHMAN, I.R. et al. Bioquímica de mamíferos. 7.ed. Rio de Janeiro: Guanabara Koogan, 1988. 620p.

WARBURG, O.; CHRISTIN, W. Isohering und kristallisation des gõrungs ferments enolase. Biochemistry Zoology, n.310, p.384-421, 1941.

ZAMBONINO-INFANTE, J.L.; CAHU, C.L.; PERES, A. Partial substitution of di- and tripepides for native proteins in sea bass diet improves Dicentrarchus labrax larva development. Journal Nutrition, v.127, p.608-614, 1997. 